\section{Revista de CIENCIAS AMBIENTALES Tropical Journal of Environmental Sciences}

Revista de Ciencias Ambientales (Trop J Environ Sci) e-ISSN: 2215-3896

(Enero-Junio, 2022) . Vol 56(1): 209-228

DOI: https://doi.org/10.15359/rca.56-1.10

Open Access: www.revistas.una.ac.cr/ambientales e-mail: revista.ambientales@una.ac.cr Rodríguez-Miranda R., Palomo-Cordero L., Padilla-Mora M., Corrales-Vargas A., Wendel de Joode B. van

\title{
Aprendizaje a través de estrategias lúdicas: una herramienta para la Educación Ambiental
}

\author{
Playful Learning: a tool for Environmental Education \\ Reichel Rodríguez-Miranda ${ }^{1}$, Luis Palomo-Cordero ${ }^{2}$, Michael Padilla-Mora ${ }^{3}$, \\ Andrea Corrales-Vargas ${ }^{4}$, Berna van Wendel de Joode ${ }^{5}$
}

[Recibido: 19 de agosto 2021, Aceptado: 11 de octubre 2021, Corregido: 16 de noviembre 2021, Publicado: 1 de enero 2022]

\section{Resumen}

[Introducción]: El aprendizaje basado en estrategias lúdicas para la educación ambiental representa una estrategia de mediación pedagógica participativa, que considera las realidades socioambientales del entorno en que está inmerso el individuo. [Objetivo]: Promover la educación ambiental, por medio de metodologías lúdicas, participativas y flexibles, para la generación de conocimiento para la prevención de la exposición a plaguicidas. [Metodología]: Con sistemas de información geográfica se calculó proximidad entre escuelas y fincas bananeras. Se diseñó una metodología lúdica constructivista para la educación ambiental de estudiantes de primer ciclo de primaria (6 8.5 años), vinculando temas ambientales con la maya curricular. Además, se diseñaron actividades educativas para sus encargados. La metodología se aplicó en 37 escuelas rurales costarricenses a 2757 estudiantes y 387 personas adultas durante 148 encuentros. [Resultados]: Un $38 \%(\mathrm{n}=14)$ de escuelas estaban ubicadas a $<100 \mathrm{~m}$ de fincas bananeras. En los talleres, la comunicación basada en el uso de diversas estrategias pedagógicas lúdicas generó un ambiente participativo, que identificó necesidades locales, construcción de saberes colectivos y conocimiento sobre efectos de la exposición a plaguicidas en salud humana y ambiental. Las personas participantes reconocieron las principales acciones preventivas para reducir la exposición a plaguicidas. [Conclusiones]: Las metodologías lúdicas, participativas y flexibles en la educación ambiental facilitaron el proceso de sensibilización a estudiantes de primer ciclo de primaria y sus madres y encargados legales de comunidades rurales sobre los riesgos de exposición a plaguicidas. La metodología usada se podrá fácilmente adaptar para su aplicación en otros estudios de ciencias ambientales.

Palabras clave: Educación ambiental; métodos participativos; plaguicidas; riesgos ambientales.

\section{Abstract}

[Introduction]: Playful learning for environmental education represents a participatory pedagogical mediation that considers the socio-environmental realities in which persons are immersed. [Objective]: To promote

1 Asistente de investigación en Programa Infantes y Salud Ambiental (ISA) del Instituto Regional de Estudios en Sustancias Tóxicas (IRET) de la Universidad Nacional (UNA), Costa Rica; reichel.rodriguez.miranda@una.ac.cr; https://orcid.org/0000-0003-1745-5477

2 Asistente de investigación en Programa Infantes y Salud Ambiental (ISA) del Instituto Regional de Estudios en Sustancias Tóxicas (IRET) de la Universidad Nacional (UNA), Costa Rica; luis.palomo.cordero@una.ac.cr; https://orcid.org/0000-0002-9561-6742

3 Académico e investigador de la División de Educación Básica (DEB), Centro de Investigación y Docencia en Educación (CIDE) de la Universidad Nacional (UNA), Costa Rica; michael.padilla.mora@una.ac.cr; https://orcid.org/0000-0002-4229-8998

4 Investigadora en Programa Infantes y Salud Ambiental (ISA) del Instituto Regional de Estudios en Sustancias Tóxicas (IRET) de la Universidad Nacional (UNA), Costa Rica; andrea.corrales.vargas@una.ac.cr; https://orcid.org/0000-0003-4050-3414

5 Académica e investigadora en Programa Infantes y Salud Ambiental (ISA) del Instituto Regional de Estudios en Sustancias Tóxicas (IRET) de la Universidad Nacional (UNA), Costa Rica; berendina.vanwendel.dejoode@una.ac.cr; https://orcid.org/0000-0001-9699-5046
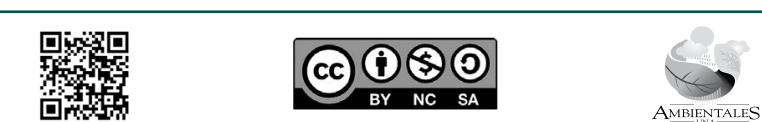

AMBIENTALES 


\section{Revista de CIENCIAS AMBIENTALES Tropical Journal of Environmental Sciences}

Revista de Ciencias Ambientales (Trop J Environ Sci) e-ISSN: 2215-3896

(Enero-Junio, 2022) . Vol 56(1): 209-228 DOI: https://doi.org/10.15359/rca.56-1.10

Open Access: www.revistas.una.ac.cr/ambientales e-mail: revista.ambientales@una.ac.cr

Rodríguez-Miranda R., Palomo-Cordero L., Padilla-Mora M., Corrales-Vargas A., Wendel de Joode B. van

environmental education, through playful, participatory, and flexible methods, to prevent pesticide exposure. [Methodology]: Using geographic information systems, the distances between schools and bananas plantations were calculated. A playful and constructivism methodology was designed for primary school students (6 - 8.5 years), and their legal guardians. Subsequently, 148 workshops were developed in 37 rural Costa Rican schools, in which 2757 children and 387 adults participated. [Results]: Thirty-eight percent $(38 \%)(n=14)$ of the schools were located at less than 100 meters from banana plantations. Playful communication generated a participatory environment, in which local needs were identified and collective knowledge was built about the effects of pesticide exposure on the environment and human health. Participants were able to identify the main preventive actions to reduce pesticide exposure. [Conclusions]: Playful, participatory, and flexible methodologies in environmental education facilitate the process of sensitizing first cycle primary school students and their parents from rural communities about the risks of exposure to pesticides. The methodology used can be easily adapted for application in other environmental science studies.

Keywords: environmental education; participatory methods; pesticides; environmental risks

\section{Introducción}

El aprendizaje a través de estrategias lúdicas en la primera infancia es identificado como la metodología más amigable y significativa para relacionarse con el contenido curricular y favorece la capacidad de indagación y resolución de problemas; su implementación motiva la curiosidad científica y ha resultado positiva en múltiples niveles (Rodríguez et al., 2017). El empleo de la lúdica desde la Concepción Metodológica Dialéctica (CMD) es estratégico para escolares en la comprensión del contexto y la reflexión de factores individuales, culturales, socioeconómicos y ambientales, que intervienen en la salud pública (López-Bolaños et al., 2018). En la mediación, los conocimientos adquiridos por medio de actividades lúdicas exploratorias deben ser reforzados, sobre todo cuando la persona participante es parte del fenómeno reflexionado (Burgos et al., 2017). Burgos et al. (2017) señalan que la indagación científica basada en la participación conduce al estudiantado a un aprendizaje significativo, donde es posible expresarse, preguntar, reflexionar, ser creativos, proponer y obtener hallazgos. En contraste, la educación ambiental mediada a través del juego como recurso didáctico, permite la comunicación sin distinciones geográficas, étnicas o sociales, y se ha posicionado como un medio para la búsqueda de soluciones a problemáticas comunitarias usuales (Pulido Santana, 2005). La incorporación de la lúdica en la educación ambiental ha evidenciado ajustes escolares internos que luego son proyectados a la comunidad en general (Pulido Santana, 2005).

En Costa Rica, al igual que otras regiones del mundo, las zonas rurales presentan problemáticas socioambientales relacionadas con las condiciones de vivienda, falta de agua potable $o$ drenaje y la acumulación de basura, que inciden sobre la salud pública y ecosistémica; el cantón de Matina en la provincia de Limón, no escapa de esta realidad (Instituto de Desarrollo Rural, 2016). El Programa de Naciones Unidas para el Desarrollo (PNUD) y Universidad de Costa Rica (UCR), lo clasifican como el cantón con el Índice de Desarrollo Humano más bajo (0.661)

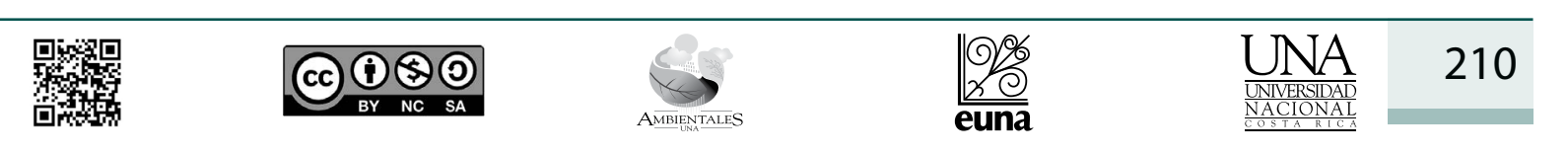




\section{Revista de CIENCIAS AMBIENTALES Tropical Journal of Environmental Sciences}

Revista de Ciencias Ambientales (Trop J Environ Sci) e-ISSN: 2215-3896

(Enero-Junio, 2022) . Vol 56(1): 209-228 DOI: https://doi.org/10.15359/rca.56-1.10

Open Access: www.revistas.una.ac.cr/ambientales e-mail: revista.ambientales@una.ac.cr Rodríguez-Miranda R., Palomo-Cordero L., Padilla-Mora M., Corrales-Vargas A., Wendel de Joode B. van

entre 2011 y 2018 (Programa de las Naciones Unidas para el Desarrollo y Universidad de Costa Rica, 2020).

Por ello, el programa Infantes y Salud Ambiental (ISA) ha abordado la investigación-extensión en esta región y estudia posibles efectos de la exposición a plaguicidas sobre la salud mediante una cohorte de nacimiento (Córdoba Gamboa et al., 2020; Mora et al., 2018; Mora et al., 2020). El Programa incorpora un enfoque ecosistémico en salud humana para promover acciones que podrían mitigar los efectos asociados con la exposición (Barraza et al., 2011, 2020). La zona del estudio se caracteriza por la siembra de monocultivos de banano, en con un área total de 104,15 km² según la Secretería Ejecutiva de Planificación Sectorial Agropecuaria., (2015), que dependen de la aplicación de hasta 27 ingredientes activos de plaguicidas colocados vía terrestre (nematicidas, herbicidas), bolsas tratadas con insecticidas y 16 tipos de fungicidas aplicados con aviones ligeros (Bravo et al., 2013). El uso de plaguicidas detona una exposición ambiental que ha sido asociada con efectos en la salud sobre el sistema nervioso y respiratorio de los infantes (Mora et al., 2018; Mora et al., 2020; Till et al., 2019; van Wendel de Joode et al., 2016). Además, se encontró que personal de centros educativos de la zona percibe un mayor riesgo por uso de plaguicidas en comparación con personal de otras entidades en Limón, lejanas del sector agrícola (Barraza et al., 2020).

El diseño de esta estrategia de abordaje pedagógico surgió con el objetivo de posicionar las metodologías lúdicas, participativas y flexibles como una herramienta para la promoción de la educación ambiental, enfocada en temáticas relacionadas con la exposición a plaguicidas en comunidades agrícolas rurales en el cantón. Las personas participantes de esta iniciativa fueron estudiantes de I ciclo de primaria (6-8.5 años) y sus tutores legales.

\section{Metodología}

\subsection{Población participante}

Se efectuaron 148 encuentros con 2757 estudiantes de primer ciclo y 387 encargados de familia de 37 escuelas (Rodríguez et al., 2020b). Los talleres fueron autorizados por la Dirección Regional (DRE) de Limón y de Sulá del Ministerio de Educación Pública (MEP) y los directores de cada escuela.

\subsection{Ubicación de centros educativos y su proximidad con bananeras}

Para planificar la ejecución de los talleres ambientales en el cantón, se identificó imágenes satelitales de las plantaciones de banano por medio de reconocimiento de paisaje y comparación con la capa de cultivos a escala 1:50 000 del Sistema de Información Territorial (Sistema Nacional de Información Territorial, 2019), en sistemas de información geográfica (ArcGIS 10.7 y Google Earth PRO).

\begin{tabular}{|c|c|c|c|c|c|}
\hline 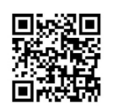 & 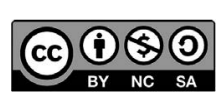 & $\underset{\text { AMBENETILES }}{3}$ & $\begin{array}{l}\frac{O O}{2} \\
\frac{2}{2} \\
\text { euna }\end{array}$ & 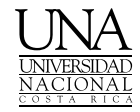 & 211 \\
\hline
\end{tabular}




\section{Revista de CIENCIAS AMBIENTALES Tropical Journal of Environmental Sciences}

Revista de Ciencias Ambientales (Trop J Environ Sci) e-ISSN: 2215-3896

(Enero-Junio, 2022) . Vol 56(1): 209-228 DOI: https://doi.org/10.15359/rca.56-1.10

Open Access: www.revistas.una.ac.cr/ambientales e-mail: revista.ambientales@una.ac.cr Rodríguez-Miranda R., Palomo-Cordero L., Padilla-Mora M., Corrales-Vargas A., Wendel de Joode B. van

Se consultó el plano catastral de cada centro educativo en el sistema de información del Registro Nacional de Costa Rica, para ingresar sus derroteros en ArcGIS 10.7. Tres escuelas no poseen plano catastral (Namaldí, San Cristóbal y Colonia Puriscaleña), en estos casos se tomó la trayectoria en campo con GPS (Garmin Montana 610) de los linderos de las propiedades según criterio del director o directora de cada escuela, para generar un archivo en formato shape.

En cada institución educativa, según la metodología de (Córdoba Gamboa et al., 2020), se calculó la proximidad con la herramienta $N E A R$, entre la línea de cultivo de banano de exportación y el segmento del perímetro más cercano del registro catastral de cada centro educativo.

\subsection{Talleres participativos con estudiantes}

\subsubsection{Propuesta metodológica y vínculo con malla curricular}

La propuesta metodológica basada en el uso de la lúdica y el constructivismo como estrategia didáctica se encuentra sustentada en la educación ambiental, la participación y los talleres como un recurso divulgativo y preventivo, planificado para los 37 centros educativos que integran el cantón de Matina en Limón, Costa Rica. Cada fase incluyó contenidos curriculares estipulados para la educación primaria costarricense de las unidades de estudio de los Programas Educativos Nacionales en Ciencias (salud humana, recursos naturales, ambiente, uso de agroquímicos y contaminación) y Estudios Sociales (desarrollo social, relieve, responsabilidad local y ruralidad) (Rodríguez et al., 2020a), y las principales temáticas abordadas a partir de investigaciones del programa ISA, principalmente sobre efectos en salud humana y ambiental. Se diseñó una propuesta integral, que además de recopilar información para futuros abordajes con esta comunidad, permitió habilitar espacios diversos para la reflexión, el análisis, las preguntas y la búsqueda de soluciones conjuntas ante las problemáticas identificadas.

\subsubsection{Actividad inicial}

Para propiciar un espacio flexible, donde la población infante participara desde sus experiencias y reflexionara sobre situaciones de la realidad comunitaria, se analizó la necesidad de emplear un juego sencillo, como "traigo carta para...", donde se solicitó a las personas participantes, posicionarse en un círculo amplio. Se explicó que si la persona facilitadora decía: “ ¡traigo carta para...", añadida por una característica con la que se sintieran identificados: “...quienes aman los confites!" o “...quienes acostumbran a jugar dentro de la finca bananera?!”, debían cambiar su posición dentro del círculo (Figura 1). La frase "traigo carta para" fue acompañada por más de 6 características relacionadas con el tema de estudio. El juego tuvo como finalidad contabilizar el total de infantes expuestos a riesgos particulares de carácter ambiental y conversar al cierre, sobre la identificación de acciones preventivas para mitigar situaciones como riegos en la vía pública, alergias, picazón o enrojecimiento ante la aplicación de plaguicidas vía aérea cuando se dirigían a la escuela.

\begin{tabular}{|c|c|c|c|c|c|}
\hline 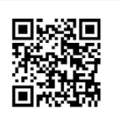 & (c) $(9)(0)$ & $\overbrace{\text { AMEIENTILES }}$ & $\begin{array}{l}\frac{9 \%}{2} \\
\frac{2}{2} \\
\text { euna }\end{array}$ & 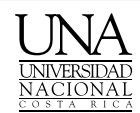 & 212 \\
\hline
\end{tabular}




\section{Revista de CIENCIAS AMBIENTALES Tropical Journal of Environmental Sciences}

Revista de Ciencias Ambientales (Trop J Environ Sci) e-ISSN: 2215-3896

(Enero-Junio, 2022) . Vol 56(1): 209-228 DOI: https://doi.org/10.15359/rca.56-1.10 Open Access: www.revistas.una.ac.cr/ambientales e-mail: revista.ambientales@una.ac.cr Rodríguez-Miranda R., Palomo-Cordero L., Padilla-Mora M., Corrales-Vargas A., Wendel de Joode B. van

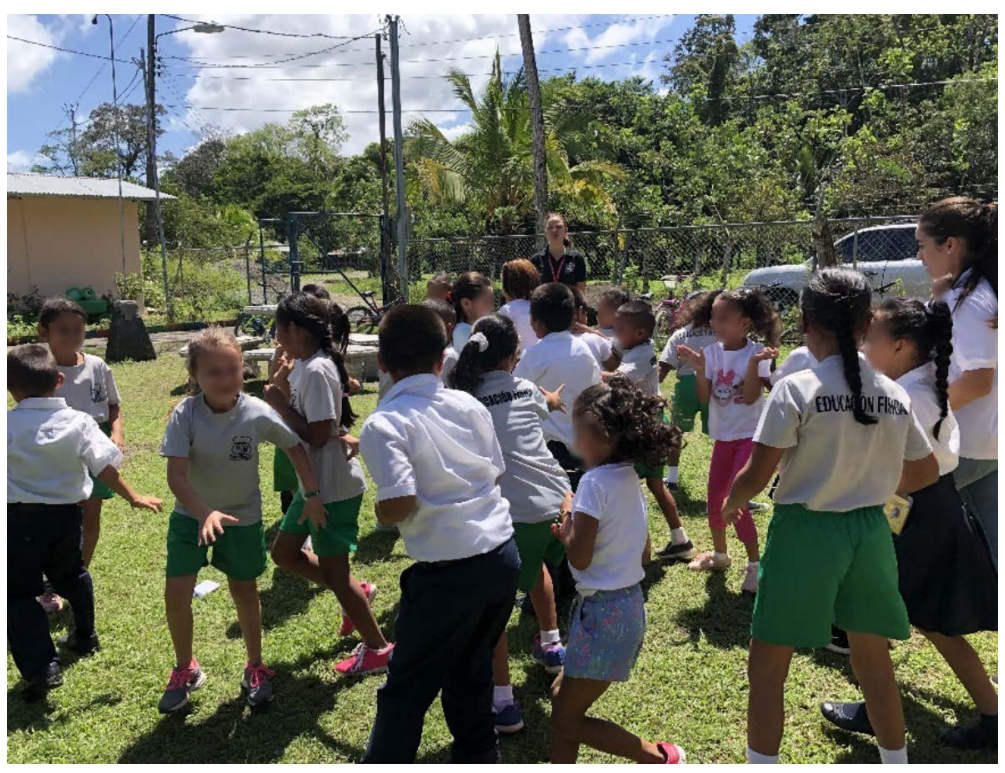

Figura 1. Juego inicial de apertura y confianza entre participantes "traigo carta para..."

Figure 1. Strat game to openness and trust between participants "I bring a letter to...".

Este espacio lúdico permitió conocer la realidad contextual y hábitos comunitarios, respecto al uso de plaguicidas, al incorporar preguntas sobre las fuentes de exposición, vinculadas con la deriva de la fumigación aérea, el ingreso a las fincas y la reutilización de bolsas celestes tratadas con insecticida:

- ¿Alguien entre ustedes ha sido regado con pequeñas gotitas que salen de la avioneta cuando se fumigan cultivos de banano?

- ¿Quién de ustedes acostumbra a jugar dentro de la finca bananera?

- ¿Cuántos de ustedes han jugado con el chemis ${ }^{6}$, utilizado para embolsar el banano?

- ¿Quién utiliza en casa, las bolsas celestes para proteger cultivos y frutas en el patio o jardín?

- Posteriormente, se mostraron imágenes impresas sobre las principales prácticas de riesgo y problemáticas locales identificadas. Las personas participantes agregaron experiencias personales y familiares relacionadas con las ilustraciones.

6 Se identificó que “chemis” es el nombre común de la bolsa celeste tratada con insecticidas para proteger el banano.

\begin{tabular}{|c|c|c|}
\hline 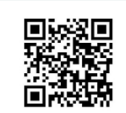 & (c) () $(0)$ & 213 \\
\hline
\end{tabular}




\section{Revista de CIENCIAS AMBIENTALES Tropical Journal of Environmental Sciences}

Revista de Ciencias Ambientales (Trop J Environ Sci) e-ISSN: 2215-3896

(Enero-Junio, 2022) . Vol 56(1): 209-228 DOI: https://doi.org/10.15359/rca.56-1.10

Open Access: www.revistas.una.ac.cr/ambientales e-mail: revista.ambientales@una.ac.cr Rodríguez-Miranda R., Palomo-Cordero L., Padilla-Mora M., Corrales-Vargas A., Wendel de Joode B. van

\subsubsection{Contexto ambiental}

Se proyectó el video "En Matina nos informamos y transformamos: Corte documental para talleres 2019” (ISA, 2019) que narra la problemática ambiental, con animaciones y grabaciones de las actividades económicas, biodiversidad del sitio, interacción entre contaminantes y la biota, salud pública e impacto sobre la salud ecosistémica. La proyección se acompañó de un intercambio dialógico, dirigido con preguntas generadoras como: ¿el agua es importante?, ¿para qué es importante el agua?, ¿han visto los insectos de agua?, ¿cómo evitar la contaminación?, acompañadas por las personas facilitadoras. Durante el diálogo, el estudiantado aportó experiencias relacionadas con la matanza de peces en su localidad, al comprender que los peces morían por la contaminación ocasionada mayoritariamente en las zonas de cultivo. Lo anterior propició aprendizajes compartidos para aplicar en casa, como: evitar el juego con bolsas celestes, jugar lejos del bananal, usar sombrilla al caminar por la vía pública, lavar inmediatamente la piel y la ropa después de ser regados, lavar ropa de trabajadores agrícolas por aparte y lavar los alimentos antes de ingerirlos. Se presentó la animación de un líder local invitando a los niños a trabajar por el cuido ambiental y se entregó una insignia con la leyenda "Cuidemos el agua", motivándolos a ser los "guardianes del ambiente" y a reflexionar en la importancia de la investigación, el ambiente y las prácticas preventivas en entornos agrícolas con mayor riesgo de exposición a plaguicidas.

\subsubsection{Laboratorio en clase}

\subsubsection{Estimulación de coordinación visomotora}

El origami es una técnica con papel que permite manipular y dar casi cualquier forma a un simple trozo de papel de múltiples dimensiones, en la que de forma paralela se impulsa la creatividad, la expresión y se estimulan funciones mentales básicas, esenciales para el aprendizaje (Zevallos et al., 2016). El estudiantado fue invitado a confeccionar su propio barco, con indicaciones modeladas, con la finalidad de observar reacciones, desarrollo visomotor y actitudes diversas durante la tarea, sumado a las habilidades que son estimuladas a través de la técnica. En dicha actividad, cada participante recibió una hoja en blanco tamaño carta y se orientó para confeccionar un barco con la técnica de origami. Se metaforizó el barco como medio de transporte para atravesar un río donde los "guardianes del ambiente" investigarán los efectos de los plaguicidas sobre la calidad del agua, al identificar los macroinvertebrados acuáticos que viven en el lecho del cuerpo de agua.

\subsubsection{Estudio de macroinvertebrados acuáticos}

El uso de recursos didáctico de manera intencionada es útil para facilitar los procesos de enseñanza-aprendizaje, al promover la estimulación sensorial de forma directa o indirecta (Morales Muñoz, 2012). Estos pueden presentarse en forma escrita, visual o concreta para apoyar

\begin{tabular}{|c|c|c|c|c|c|}
\hline 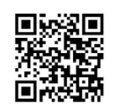 & (c) (i) $(9)$ & $\underset{\text { AMBENETILES }}{3}$ & $\frac{1 \%}{2 \%}$ & $\frac{\text { UNA }}{\frac{\text { UNIVERSIDAD }}{\text { NACIONAL }}}$ & 214 \\
\hline
\end{tabular}




\section{Revista de CIENCIAS AMBIENTALES Tropical Journal of Environmental Sciences}

Revista de Ciencias Ambientales (Trop J Environ Sci) e-ISSN: 2215-3896

(Enero-Junio, 2022) . Vol 56(1): 209-228 DOI: https://doi.org/10.15359/rca.56-1.10

Open Access: www.revistas.una.ac.cr/ambientales e-mail: revista.ambientales@una.ac.cr Rodríguez-Miranda R., Palomo-Cordero L., Padilla-Mora M., Corrales-Vargas A., Wendel de Joode B. van

la labor pedagógica (Morales Muñoz, 2012). Para la propuesta se decidió utilizar información y material gráfico sobre los tipos de macroinvertebrados acuáticos que habitan en aguas de buena o mala calidad (Echeverría-Sáenz et al., 2018). Se tomó como referencia el índice de biomonitoreo de calidad de agua BMWP’CR-2007 y guías fotográficas (Asamblea Legislativa, 2007; Springer et al., 2007). Además, se mostró a los niños y niñas dónde se localizan dichos organismos en la cadena trófica, mientras acostados en el suelo con los ojos cerrados se les presentó una historia imaginaria, donde ellos navegaban en su barco de papel, veían distintas especies y, por último, se hicieron preguntas relacionadas con el viaje, motivando al aprecio por el quehacer investigativo. Para iniciar con la etapa de estaciones, se les mostraron imágenes impresas con la cadena trófica con la que se explicó con detalle, cómo funciona la ingesta de un macroinvertebrado de agua mala por un pez más grande y así sucesivamente estos llegan a ser ingeridos por el ser humano.

Los talleres se llevaron a cabo en las aulas, debidamente acondicionadas por estaciones de trabajo. Sobre las mesas, se colocó placas Petri con macroinvertebrados que habitan en aguas de buena o mala calidad (capturados previamente por los facilitadores), una lupa, un pincel y una tarjeta de identificación con datos del insecto (nombre común, nombre científico y agua donde habita). En dichas estaciones, la niñez participante podía movilizarse en forma circular con un grupo de pares para conocer distintos macroinvertebrados y manipularlos con el pincel, donde lograron identificar los macroinvertebrados que habitan en agua de buena o mala calidad, situación relacionada con la contaminación. En una estación adicional, se instaló un estereoscopio para observar de cerca las características taxonómicas de los insectos, en el que cada estudiante tuvo oportunidad para visualizar con el estereoscopio y hacer preguntas o comentarios relacionados con la temática. Se finalizó con un diálogo breve sobre las precauciones al ingresar a ríos en presencia de insectos de agua de mala o muy mala calidad, en el que el estudiantado reconoció la importancia de observar antes de entrar y la entrega de material impreso con datos ilustrativos sobre los riesgos de exposición a plaguicidas.

\subsection{Talleres participativos con personas adultas}

Este encuentro se diseñó con un enfoque más explícito, acompañado de material informativo y preventivo sobre los efectos de sustancias tóxicas en la salud humana y ambiental. Se estableció espacios para el diálogo reflexivo sobre problemáticas que aquejan a cada comunidad; así como las prácticas de riesgo de exposición comunes en la zona. Se proyectó el corto audiovisual titulado "Salud y plaguicidas en el Caribe: un llamado general" (Instituto Regional de Estudios en Sustancias Tóxicas \& Centro de Investigación y Docencia en Educación., 2018), que contextualiza la situación ambiental y resume la labor de investigadores del IRET sobre los impactos por aplicación de plaguicidas en la salud. También se tomó como referencia resultados previos del programa ISA, enfatizando la posible afectación del neurodesarrollo de infantes por la exposición a plaguicidas (Córdoba Gamboa et al., 2020; Mora et al., 2018; van Wendel de Joode et al., 2016).

\begin{tabular}{|c|c|c|c|c|}
\hline 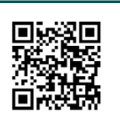 & (c) (i) () & $\overbrace{\text { AMBENTILES }}$ & $\frac{\mid \sigma o \%}{\text { euna }}$ & 215 \\
\hline
\end{tabular}




\section{Revista de CIENCIAS AMBIENTALES Tropical Journal of Environmental Sciences}

Revista de Ciencias Ambientales (Trop J Environ Sci) e-ISSN: 2215-3896

(Enero-Junio, 2022) . Vol 56(1): 209-228 DOI: https://doi.org/10.15359/rca.56-1.10

Open Access: www.revistas.una.ac.cr/ambientales e-mail: revista.ambientales@una.ac.cr Rodríguez-Miranda R., Palomo-Cordero L., Padilla-Mora M.,

Corrales-Vargas A., Wendel de Joode B. van

$\mathrm{Al}$ abrir el espacio para el diálogo, una vez finalizado el video, las personas participantes mencionaron experiencias ocurridas en su localidad, con carácter negativo y vinculado con las prácticas agrícolas de la zona.

Posteriormente, se expuso sobre los requisitos que debe cumplir, la fumigación aérea según lo indicado por el reglamento 31520 sobre actividades de aviación agrícola (Asamblea Legislativa, 2003) y las condiciones de empleo de quienes laboran en fincas bananeras, enfatizando en temas relacionados con: jornadas, manipulación de plaguicidas, equipos de protección personal, tiempos de alimentación y la denuncia ambiental. Asimismo, se atendieron consultas sobre rezagos educativos en la niñez y las actividades desarrolladas en los talleres con estudiantes, por lo que se orientó a los padres de familia en técnicas lúdicas y económicas aplicables en casa (Cuadro 1), para el refuerzo de las funciones cognitivas, involucradas en el aprendizaje.

Cuadro 1. Técnicas de compensación como recurso didáctico lúdico compartidas en el taller con las personas adultas.

Table 1. Compensation techniques as a recreational didactic resource shared in the workshop with adults.

\begin{tabular}{ll}
\hline $\begin{array}{l}\text { Técnica de } \\
\text { compensación }\end{array}$ & Beneficios \\
\hline Origami & $\begin{array}{l}\text { Mejora en la coordinación bilateral ojo-mano, incrementa la fuerza y sensibilidad de los dedos, } \\
\text { mejora la categorización de color, tamaño y figura fondo (Durán Ccorachua, \& Paucar Meza, 2016). } \\
\text { Desarrolla habilidades de organización, procesamiento múltiple, secuenciación, la concentración, } \\
\text { creatividad y memoria (Si Estrada, \& Hernández Ajú, 2015). }\end{array}$ \\
Malabares & $\begin{array}{l}\text { La práctica constante de ejercicios con malabares, contribuye en dos áreas estrechamente vinculadas: } \\
\text { habilidades motrices y coordinación (Carreño Torres, 2018). } \\
\text { Las personas participantes pueden dar sentido al mundo a través de actividades como los malabares, } \\
\text { porque se concientizan de sus movimientos en pro de mejorar su coordinación y capacidades } \\
\text { motoras (Carreño Torres, 2018). A los beneficios, se suma la oportunidad de propiciar una mejor } \\
\text { interacción con el medio circundante (Carreño Torres, 2018). }\end{array}$ \\
\hline
\end{tabular}

Para continuar, se compartió un espacio de comensalidad que permitió paralelamente el desarrollo de la técnica de "finger print", que consiste en el uso de huellas dactilares con tinta o pintura, para personalizar macetas plásticas. Dicha técnica fue seleccionada para fomentar el pensamiento creativo y metaforizar la huella familiar y comunitaria que se puede legar mediante acciones positivas, que incluyen el empleo de acciones preventivas ante la exposición a plaguicidas. Mientras cada participante decoraba su maceta, se documentó temas de interés manifestados, para futuros talleres.

\begin{tabular}{|c|c|c|}
\hline 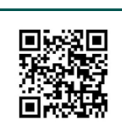 & (c) (i) () (2) (2) & 216 \\
\hline
\end{tabular}




\section{Revista de CIENCIAS AMBIENTALES Tropical Journal of Environmental Sciences}

Revista de Ciencias Ambientales (Trop J Environ Sci) e-ISSN: 2215-3896

(Enero-Junio, 2022) . Vol 56(1): 209-228 DOI: https://doi.org/10.15359/rca.56-1.10 Open Access: www.revistas.una.ac.cr/ambientales e-mail: revista.ambientales@una.ac.cr Rodríguez-Miranda R., Palomo-Cordero L., Padilla-Mora M., Corrales-Vargas A., Wendel de Joode B. van

\section{Resultados}

\subsection{Análisis de proximidad y aumento de frontera agrícola}

Se contabilizó 35 escuelas dentro del cantón de Matina, una en el cantón de Turrialba (Namaldí) y otra en el cantón de Siquirres (Madre de Dios). En la (Figura 2) se observan las escuelas agrupadas por color según distancia con respecto a la finca bananera: menos de $100 \mathrm{~m}$ (rojo), 100-500 m (naranja) y más de $500 \mathrm{~m}$ (azul).

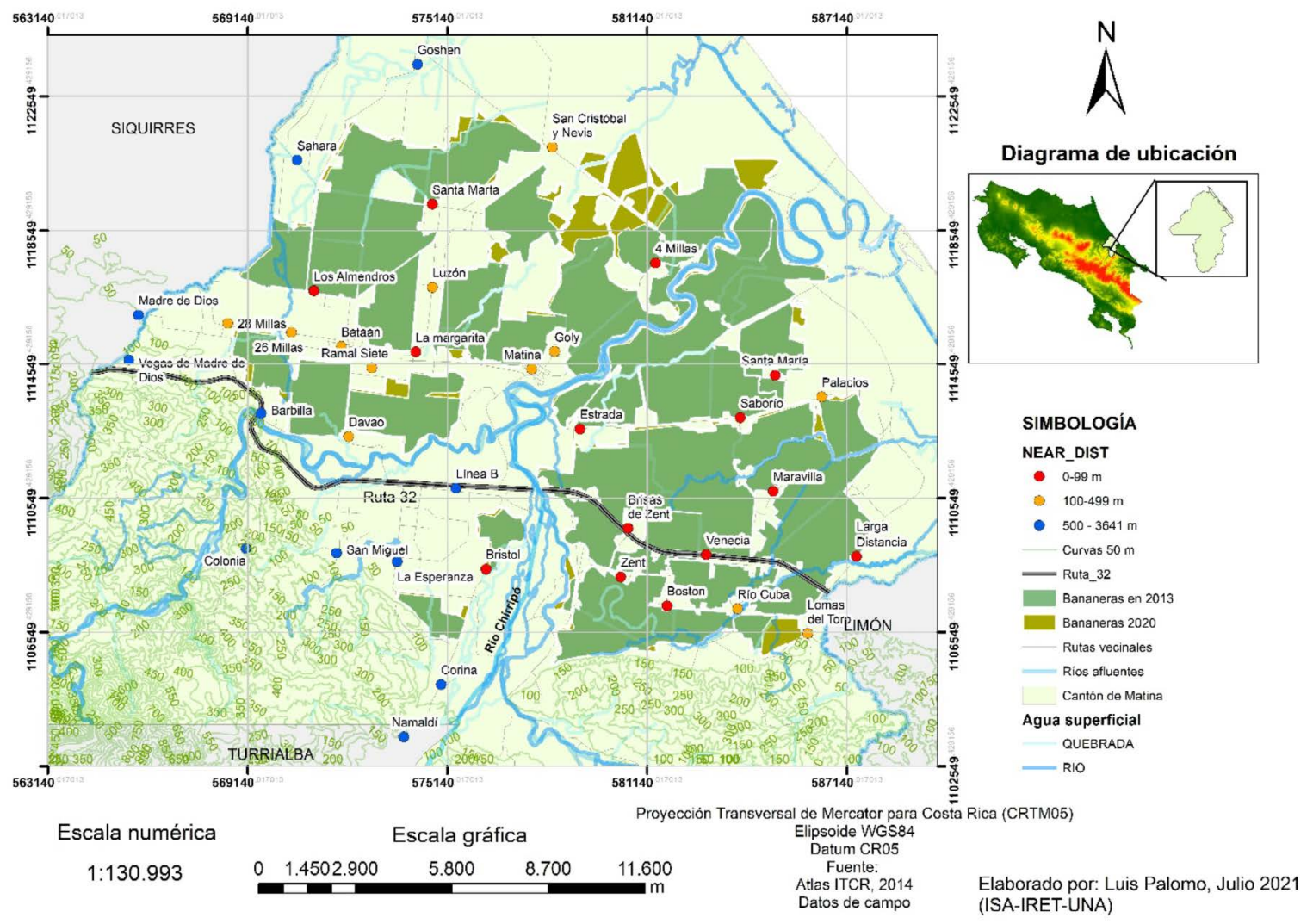

Figura 2. Proximidad entre escuelas visitadas y capa de cultivo banano de exportación.

Figure 2. Schools and banana plantains proximity.

Un $38 \%(n=14)$ de los centros educativos, se encuentran a menos de 100 m. 32,4\% ( $n=12)$ se encuentran entre 100 y $500 \mathrm{~m}$. Las 11 escuelas restantes, se localizan a más de $500 \mathrm{~m}$.

Durante el desarrollo de talleres en comunidades como 4 Millas, San Cristóbal, San Juan (Goshen) y Sahara, con población adulta, los participantes mencionaron que percibían un crecimiento de la frontera agrícola hacia la zona costera. El reconocimiento de paisaje realizado para

\begin{tabular}{|c|c|c|}
\hline 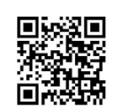 & (c) (P) & 217 \\
\hline
\end{tabular}




\section{Revista de CIENCIAS AMBIENTALES Tropical Journal of Environmental Sciences}

Revista de Ciencias Ambientales (Trop J Environ Sci) e-ISSN: 2215-3896

(Enero-Junio, 2022) . Vol 56(1): 209-228 DOI: https://doi.org/10.15359/rca.56-1.10 Open Access: www.revistas.una.ac.cr/ambientales e-mail: revista.ambientales@una.ac.cr Rodríguez-Miranda R., Palomo-Cordero L., Padilla-Mora M., Corrales-Vargas A., Wendel de Joode B. van

este estudio, se midió un área sembrada de banano de $142.46 \mathrm{~km}^{2}$, y evidencia un aumento de las áreas de cultivo al comparar con capas del 2013 (Figura 2).

\subsection{Factores de riesgo de exposición}

Producto del juego inicial ("traigo carta para..."), se contabilizaron algunos factores de exposición a plaguicidas. La (Figura 3), presenta solo información de diez escuelas, debido a datos faltantes.

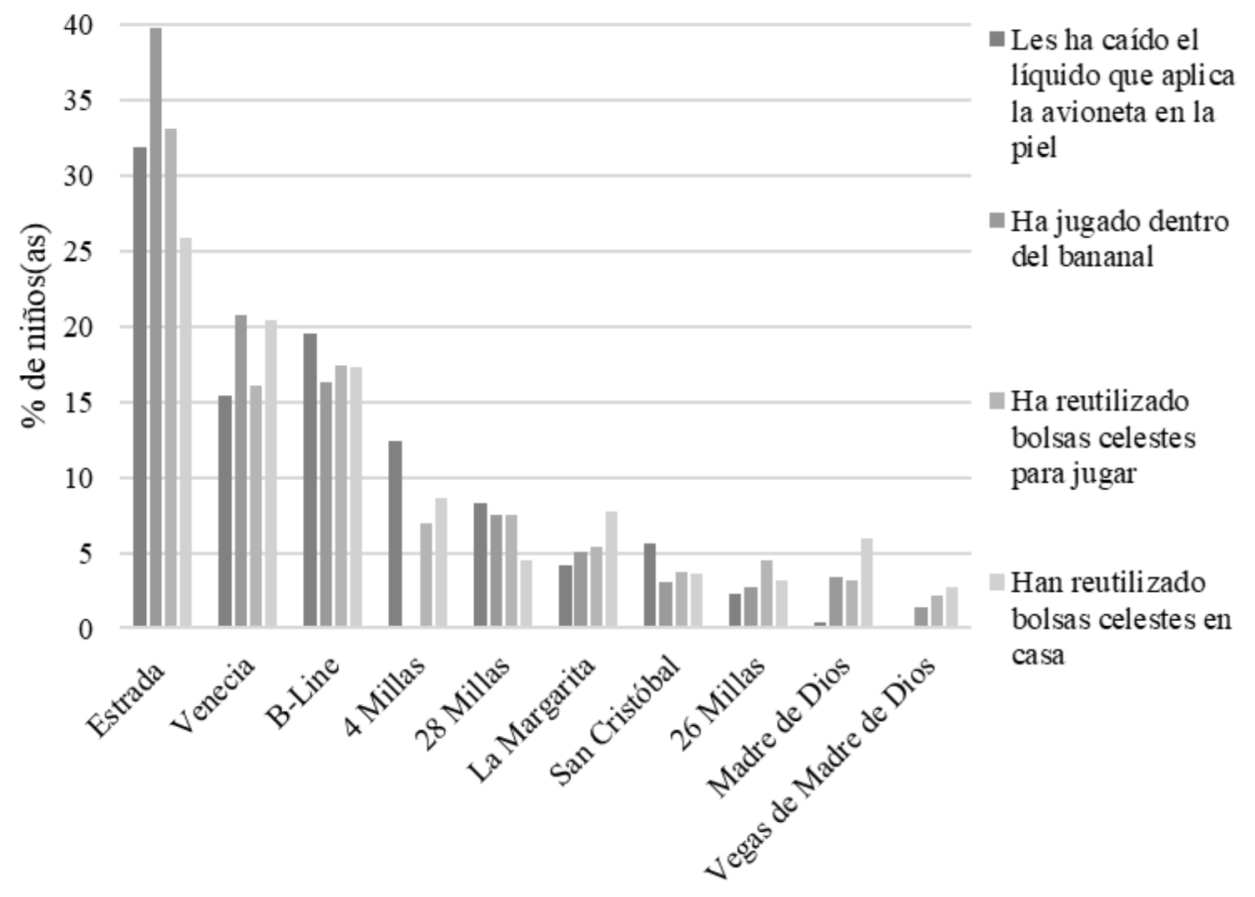

Escuelas

Figura 3. Factores de riesgo de exposición reportados por estudiantes de 10 centros educativos en Matina Figure 3. Exposure risk factors reported by students of 10 schools from Matina.

En comunidades como Estrada, B-line y Venecia, $32 \%$, 20 \% y $15 \%$ de los niños y niñas indicaron que alguna vez les había caído sobre la piel, el líquido aplicado por la avioneta (deriva). Para las mismas escuelas, un $40 \%, 16 \%$, y $21 \%$ sugiere haber ingresado a las fincas para jugar, mientras un $33 \%, 17$ \% y $16 \%$ confirma el re-uso de bolsas celestes para el juego. Este último, se mencionó de forma reiterada por el estudiantado en la escuela Estrada, reportado mayoritariamente en cultivos caseros.

\begin{tabular}{|c|c|c|}
\hline 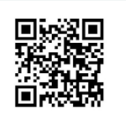 & (c) () () () & 218 \\
\hline
\end{tabular}




\section{Revista de CIENCIAS AMBIENTALES Tropical Journal of Environmental Sciences}

Revista de Ciencias Ambientales (Trop J Environ Sci) e-ISSN: 2215-3896

(Enero-Junio, 2022) . Vol 56(1): 209-228

DOI: https://doi.org/10.15359/rca.56-1.10

Open Access: www.revistas.una.ac.cr/ambientales e-mail: revista.ambientales@una.ac.cr Rodríguez-Miranda R., Palomo-Cordero L., Padilla-Mora M., Corrales-Vargas A., Wendel de Joode B. van

\subsection{Andamiaje de saberes en talleres con población infantil}

Los hallazgos de los talleres se presentan sistematizados según el orden de actividades (Cuadro 2). Esta información se caracteriza por la libertad con que los participantes expresaron vivencias y hábitos vinculados con la exposición a plaguicidas.

Cuadro 2. Sistematización de observaciones de talleres participativos con estudiantes.

Table 2. Systematization of observations of participatory workshops with students.

\begin{tabular}{ll}
\hline Actividad & Sistematización \\
\hline Actividad inicial & Se observó un gusto particular y respuestas positivas ante el uso del juego y otras estrategias \\
"Traigo carta para... & $\begin{array}{l}\text { lúdicas en ambientes escolarizados. Al estudiantado le agradan las actividades con } \\
\text { movimiento, se muestran sonrientes y prestan atención al sentido del juego. } \\
\text { La familiaridad con la que las y los estudiantes compartieron experiencias fue muy } \\
\text { enriquecedora y denotó rasgos de confianza. }\end{array}$ \\
& Se identificaron situaciones locales en breves minutos, se reflexionó en la problemática local y \\
& el estudiantado manifestó algunas posibles medidas preventivas. \\
& La población participante externó prácticas de riesgo comunes, tanto dentro como fuera de los \\
& hogares, que aumentan el riesgo de exposición a plaguicidas. \\
& La implementación de láminas ilustrativas con actividades comunes en el cantón motivó el \\
& diálogo y la conversación en torno a experiencias personales similares. \\
& Los facilitadores percibieron desconocimiento parcial sobre las sustancias aplicadas con \\
& acción biocida y sus riesgos a la salud, corroborado por el juego y por prácticas manifestadas \\
& como: ingresar al bananal para jugar o reutilización de bolsas celestes en casa. Un sector de la \\
población reitera abiertamente haber recibido gotas de deriva en el cuerpo (Ver Figura 3) y en & distintas ocasiones, haber experimentado reacciones alérgicas en la piel.
\end{tabular}

Contexto Ambiental con video

Estimulación de coordinación visomotora
Surgieron experiencias y consultas relacionadas con la situación ambiental. Parte del estudiantado comentó haber presenciado matanzas de peces, riegos aéreos, alergias, uso de bolsas celestes en el hogar y otras prácticas de riesgo para la salud ecosistémica y humana, que idealmente deben ser sustituidas por otras más preventivas.

El estudiantado prestó mucha atención a los facilitadores en la construcción del barco. Para la mayoría, fue la primera vez que hicieron origami, y por ende la elaboración del barco fue retador. Su elaboración incluía doce pasos, algunos niños y niñas requirieron o solicitaron apoyo desde el primero. Otros participantes se rendían con facilidad, empleaban frases como "no puedo" acompañado de lenguaje corporal denotando frustración o comparaban su barco con el de sus pares. Se abordó esta situación inmediatamente mediante el uso de un lenguaje que contribuya al autoconcepto positivo. Para otros, fue sencillo identificar que se construiría un barco, se adelantaron y luego, apoyaron a sus pares.

Todos los niños/as participantes lograron finalizar el barco, con o sin acompañamiento, inclusive, algunos emplearon otros pasos para lograr el objetivo. Se observó que el logro de haber construido el barco fue muy motivador para la gran mayoría del estudiantado. El traslado del contenido visual (modelaje de la actividad por la persona facilitadora) al papel, fue una tarea compleja para decenas de estudiantes, en todas las escuelas, lo cual, reveló la poca existencia de actividades de este tipo a lo interno de las aulas.

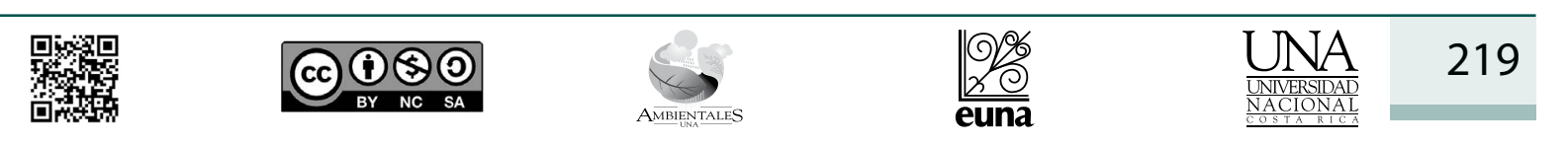




\section{Revista de CIENCIAS AMBIENTALES Tropical Journal of Environmental Sciences}

Revista de Ciencias Ambientales (Trop J Environ Sci) e-ISSN: 2215-3896

(Enero-Junio, 2022) . Vol 56(1): 209-228 DOI: https://doi.org/10.15359/rca.56-1.10

Open Access: www.revistas.una.ac.cr/ambientales e-mail: revista.ambientales@una.ac.cr Rodríguez-Miranda R., Palomo-Cordero L., Padilla-Mora M., Corrales-Vargas A., Wendel de Joode B. van

\begin{tabular}{ll}
\hline Actividad & Sistematización \\
\hline Estudio de & La niñez participante se mostró interesada en la forma de los macroinvertebrados, realizó \\
macroinvertebrados & $\begin{array}{l}\text { preguntas, utilizaron su pincel para darles vuelta y detallarlos desde toda óptica. } \\
\text { La distribución del espacio permitió movilidad y rotación en cada una de las estaciones, } \\
\text { acuáticos }\end{array}$ \\
& $\begin{array}{l}\text { La niñez utilizó todos los recursos disponibles para identificar los insectos de agua buena o } \\
\text { mala calidad. Este espacio estuvo caracterizado por anécdotas infantiles en el río, dónde veían } \\
\text { o jugaban con los macroinvertebrados. }\end{array}$ \\
\hline
\end{tabular}

\subsection{Talleres con población adulta}

Con la población adulta, se discutieron cuatro temas transversales: reglamento de aviación agrícola (decreto 31520), denuncia ambiental, legislación en derechos laborales de quienes trabajan en las bananeras y estrategias el desarrollo cognitivo infantil.

Mediante el dialogo reflexivo, algunas personas participantes se refirieron al desconocimiento generalizado en la zona sobre la legislación existente y la forma de efectuar una denuncia ambiental respecto a la aplicación de plaguicidas. Otras personas indicaron conocer el proceso; sin embargo, hicieron énfasis al temor que invade a una persona trabajadora de la bananera, con solo pensar en denunciar incumplimientos, a causa de las posibles represalias que se podrían presentar en su contra o bien, en la de sus familiares que dependen económicamente de dicho trabajo. Pocas personas asistentes confirmaron haber interpuesto denuncias anónimas, algunas atendidas de forma satisfactoria mientras otras continuaban sin respuesta. Las personas participantes expresaron tres limitantes para la interposición de denuncias. Primero, si el denunciante trabaja en la bananera o tiene familiares que lo hacen, podría ver comprometida su estabilidad laboral. En los talleres, se manifestó: "Hay gente que ha perdido su trabajo después de denunciar a la bananera por contaminación”. Segundo, el desconocimiento del proceso de denuncia, sus requisitos y la entidad encargada de ejecutar el proceso. Tercero, solicitud de datos complejos en el momento de realizar la denuncia, como número de matrícula de la avioneta.

Las personas participantes hicieron mención sobre las extensas jornadas laborales en las fincas bananeras, la fumigación aérea de plaguicidas y otras prácticas de aplicación comunes en la zona, y la ausencia de barreras naturales en zona residenciales, el poco o nulo uso de equipo de protección personal dentro de ciertas fincas bananeras, , el ingreso al hogar con ropa usada para el trabajo en la bananera, y percepción de afectación de la salud respiratoria y dérmica de las familias viviendo en la zona, y, por otra parte, los beneficios que las empresas bananeras han brindado a la escuela o a la localidad. También mencionaron el uso de plaguicidas domésticos y la preocupación por el rendimiento académico del estudiantado. Por tal motivo, se resaltó la importancia de aplicar medidas preventivas ante la exposición a plaguicidas como: lavado de ropa del trabajador bananero por aparte, bañarse tras la jornada laboral y antes de realizar contacto físico con la familia, evitar el ingreso al hogar con botas o zapatos de trabajo, evitar el tránsito por espacios donde se fumiga, esperar media hora dentro de la vivienda mientras se fumiga,

\begin{tabular}{|c|c|c|}
\hline 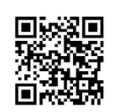 & (c) () () () & 220 \\
\hline
\end{tabular}




\section{Revista de CIENCIAS AMBIENTALES Tropical Journal of Environmental Sciences}

Revista de Ciencias Ambientales (Trop J Environ Sci) e-ISSN: 2215-3896

(Enero-Junio, 2022) . Vol 56(1): 209-228 DOI: https://doi.org/10.15359/rca.56-1.10

Open Access: www.revistas.una.ac.cr/ambientales e-mail: revista.ambientales@una.ac.cr Rodríguez-Miranda R., Palomo-Cordero L., Padilla-Mora M., Corrales-Vargas A., Wendel de Joode B. van

sembrar barreras naturales alrededor de la casa, y utilizar elementos naturales para ahuyentar plagas en cultivos caseros en vez de usar plaguicidas químicos, entre otras.

Durante la aplicación de la técnica finger print, se conversó con las personas asistentes sobre necesidades e intereses. Dentro de los temas mencionados por asistentes al taller están: emprendimiento, administración de finanzas, agricultura alternativa, acompañamiento pedagógico infantil, nutrición, actividad física y contaminación del agua; relacionados con la salud integral. Algunos participantes, expresaron interés por continuar sus estudios en educación superior o tecnificada.

\section{Discusión}

La metodología lúdica-participativa facilitó el proceso de sensibilización sobre los riesgos del uso de plaguicidas en la salud y permitió compartir resultados científicos generados por ISA. La realización de los talleres generó nueva información y una construcción colectiva de conocimientos en un ambiente semiestructurado y creativo. La información recopilada permite comprender situaciones relacionadas con la exposición a plaguicidas en la zona. En campo, esta información fue utilizada de forma inmediata durante las capacitaciones para reflexionar de forma colectiva sobre las medidas de precaución necesarias de implementar.

La devolución de resultados comúnmente se realiza en sitios web o revistas científicas; sin embargo, parte de la responsabilidad de la investigación-acción involucra compartir, comunicar y dosificar la información a la edad y escolaridad de las audiencias, impulsando saberes colectivos. Los métodos de aprendizaje a través de estrategias lúdicas permiten al estudiantado apropiarse de la información, participar activamente y expresar con confianza sus experiencias relacionadas con la exposición a plaguicidas (López-Bolaños et al., 2018). Los comentarios relacionados con fuentes de contaminación estuvieron acompañados por la reflexión inmediata sobre repercusiones en salud y ecosistemas, seguido por propuestas conjuntas para mitigarlas tales como: el uso de sombrillas en camino al centro educativo, el evitar salir mientras se hacen aplicaciones aéreas y evitar jugar en espacios lejos del bananal. Además, el grupo de estudiantes logró detallar las vías de exposición del cuerpo humano, haciendo hincapié en la protección de órganos receptores como: ojos, nariz, boca y piel. En algunas escuelas, en especial en las más cercanas a las bananeras, la población infantil demostró estar familiarizada con conceptos como: plaguicidas, plagas y veneno, además comprendió con mayor facilidad la función de la avioneta y la bolsa celestre y efectos adversos en la salud: alergias cutáneas e irritación ocular, al contacto con sustancias tóxicas, particularmente expuestos en el juego "Traigo carta para..." al iniciar el taller.

La metodología aplicada contenía componentes de la educación ambiental basados en la vinculación armónica que debe prevalecer en la relación ser humano-naturaleza. El trabajo de los facilitadores consistió en orientar a la población participante en su comprensión de ser pertenecientes al sistema ecológico, tomando como referencia el enfoque biocéntrico, que rechaza la dominancia humana sobre los otros seres de la comunidad planetaria. El proyectar

\begin{tabular}{|c|c|c|c|c|c|}
\hline 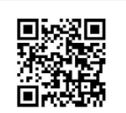 & (c) (i) (9) & $\overbrace{\text { AMBIINTALS }}^{3}$ & $\frac{\mid \% \%}{\text { euna }}$ & $\frac{\text { UNA }}{\frac{\text { UNIVERSIDAD }}{\text { UNACIONAL }}}$ & 221 \\
\hline
\end{tabular}




\section{Revista de CIENCIAS AMBIENTALES Tropical Journal of Environmental Sciences}

Revista de Ciencias Ambientales (Trop J Environ Sci) e-ISSN: 2215-3896

(Enero-Junio, 2022) . Vol 56(1): 209-228 DOI: https://doi.org/10.15359/rca.56-1.10

Open Access: www.revistas.una.ac.cr/ambientales e-mail: revista.ambientales@una.ac.cr Rodríguez-Miranda R., Palomo-Cordero L., Padilla-Mora M., Corrales-Vargas A., Wendel de Joode B. van

este mensaje requirió la implementación de espacios altamente participativos y otros más conductuales. Los primeros resultaron más pertinentes para comprender el riesgo de exposición a sustancias tóxicas y su modo de actuar sobre el ecosistema, lo anterior, ante la complejidad técnico-científica de comprender el comportamiento de agentes xenobióticos una vez disponibles e ingresados a los diferentes compartimentos ambientales (suelo, agua y aire). Para temas como los niveles tróficos y calidad del agua, se implementó técnicas apoyadas en material visual, creativo y flexible; que fomentaron la curiosidad científica. El uso de materiales didácticos durante abordajes conductistas de corta duración provocó la aceptación de nuevo saberes que el grupo de estudiantes empleó en sus intervenciones de espacios participativos. La alternancia de ambas técnicas es necesaria para captar períodos de atención, construir nuevos saberes y para que exista la oportunidad de manipular material concreto, estrechamente relacionado con el aprendizaje significativo (Morales Muñoz, 2012).

La georreferenciación de los centros educativos permitió actualizar información sobre las distancias entre escuelas y fincas bananeras, evidenciando un aumento de $9 \%$ en áreas sembradas con banano, durante la última década (Córdoba Gamboa et al., 2020). Desde una perspectiva de posible deriva de plaguicidas aplicados en fincas, es preocupante que un $38 \%$ de los centros educativos se encuentra a una distancia $<100 \mathrm{~m}$ con respecto a la bananera más cercana. Esto explica la percepción de personas trabajadoras de escuelas aledañas a las fincas, quienes perciben un mayor riesgo del uso de plaguicidas respecto a otras regiones de la provincia, donde las poblaciones están ubicadas menos frecuentemente cercanas a extensas fincas agrícolas de monocultivo (Barraza et al., 2020). Según la legislación sobre aviación agrícola costarricense, debe respetarse una franja de 100 metros como zona de amortiguamiento, sin aplicar plaguicidas vía aérea; en caso de contar con una zona de amortiguamiento más alta que el dosel de las plantas y con un ancho de 30 metros, la franja se reduce a 30 metros (Reglamento para las actividades de la Aviación Agrícola, 2003). Sin embargo, en otros países de América Latina, se recomiendan zonas de amortiguamiento mayores para fumigación aérea, tal es el caso de Ecuador (200 metros) (Ministerios de Agricultura, Ganadería, Acuacultura y Pesca [MAGAP] et al., 2014); Uruguay, Brasil, Argentina (500 metros), mientras para aplicaciones terrestres se solicitan hasta 300 metros en Uruguay (especialmente zonas aledañas a centros educativos); 200 metros en Chile y Paraguay y 100 metros en Argentina, respectivamente para zonas residenciales (Felsot et al., 2011). Esto sugiere que en Costa Rica se debe aumentar la zona de amortiguamiento sin aplicación aérea de plaguicidas para zonas escolares y residenciales, con el fin de reducir la exposición ambiental.

Aparte de la exposición ambiental por vivir a poca distancia de campos agrícolas con uso de plaguicidas, existen fuentes adicionales de exposición ambiental y para-ocupacional descritas en la (Figura 2), las cuales responden a un conjunto de prácticas naturalizadas en los hogares, especialmente porque en la mayoría de las familias hay trabajadores de fincas bananeras (van Wendel de Joode et al., 2016). La Concepción Metodológica Dialéctica fortaleció la comprensión de estas prácticas, tanto para adultos como para menores de edad, a partir de métodos

\begin{tabular}{|c|c|c|c|c|}
\hline 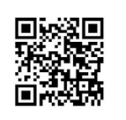 & (c) (1) $\$(0)$ & $\underset{\text { AMBENETILES }}{3}$ & $\frac{1 \%}{\text { euna }}$ & 222 \\
\hline
\end{tabular}




\section{Revista de CIENCIAS AMBIENTALES Tropical Journal of Environmental Sciences}

Revista de Ciencias Ambientales (Trop J Environ Sci) e-ISSN: 2215-3896

(Enero-Junio, 2022) . Vol 56(1): 209-228 DOI: https://doi.org/10.15359/rca.56-1.10

Open Access: www.revistas.una.ac.cr/ambientales e-mail: revista.ambientales@una.ac.cr Rodríguez-Miranda R., Palomo-Cordero L., Padilla-Mora M., Corrales-Vargas A., Wendel de Joode B. van

participativos lúdicos; además, fomentó el pensamiento crítico y creativo en los talleres, despertando el interés por diversificar las fuentes de ingresos económicos familiares, cultivar productos libres de plaguicidas, sembrar árboles nativos en zonas de amortiguamiento a la deriva y transferir conocimientos a otros miembros de la comunidad para promover mejoras en la calidad ambiental y la salud pública (López-Bolaños et al., 2018). La indagación científica permitió articular las interrelaciones entre contaminación y recursos ecosistémicos; al estar implicados los estudiantes dentro del fenómeno estudiado. De esta manera, se fortalecen los roles de acción y responsabilidad social en su comunidad; fundamentados en la prevención y promoción de prácticas agrícolas sostenibles (Burgos et al., 2017; López-Bolaños et al., 2018).

En cuanto a la relación entre el contenido de los talleres realizados con la población estudiantil y las temáticas curriculares enseñadas en los centros educativos, establecidos por el Ministerio de Educación, términos como laboratorio, insignia e investigadores, el material empleado, y la organización del espacio añadieron un alto valor a la información y conformaron una ruta significativa para el aprendizaje, estimulando la indagación científica. En consecuencia, se constituyó un ambiente áulico apropiado, innovador, con mayor atención a instrucciones y menor pesimismo.

Lo anterior fue parecido a un proyecto realizado por Valerio-Hernández et al., (2015), quienes aplicaron una selección creativa de técnicas para la mediación pedagógica para atender efectos del cambio climático a nivel local. Otro aspecto positivo para resaltar de nuestra jornada de talleres participativos fue el alcance y la integración de tres actores fundamentales: niñez, familia y comunidad educativa, similar a la experiencia planteada por (Valerio-Hernández et al., 2015). Por lo anterior, los talleres se convierten en un referente para futuras acciones, por los recursos utilizados, las posibilidades de adaptación metodológica e integración de técnicas compensatorias como el origami, beneficiosas para la población adulta e infante, al estimular procesos cognitivos, motora fina, los sentidos y el refuerzo de funciones asociadas al aprendizaje (Carreño Torres, 2018). Para el trabajo lúdico con niños, se sugiere la utilización del factor sorpresa, donde se administren ritmos y momentos. Es indispensable, considerar elementos ambientales externos que pueden interferir en la recepción de lo comunicado.

\section{Conclusiones}

Resulta importante que la educación ambiental incluya procesos lúdicos que impliquen movimiento pues promueven ambientes de confianza y participación reflexiva. Además, permiten al docente conocer la realidad contextual del estudiantado participante y apoyan la selección de contenidos prioritarios. Los talleres son útiles para identificar prácticas de riesgo y posibles medidas de prevención. En este caso particular, para mitigar los efectos de los plaguicidas en el cantón tanto en el ambiente como en la salud. Los talleres pueden generar reflexión en temas de interés social y económico, como: la importancia en la diversificación de cultivos, las repercusiones de los monocultivos para el medio ambiente y la salud y a la importancia de conocer e

\begin{tabular}{|c|c|c|c|c|}
\hline 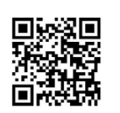 & (c) (1) $\$(0)$ & $\overbrace{\text { AMBIENTIES }}$ & $\frac{9 \%}{2 \%}$ & 223 \\
\hline
\end{tabular}




\section{Revista de CIENCIAS AMBIENTALES Tropical Journal of Environmental Sciences}

Revista de Ciencias Ambientales (Trop J Environ Sci) e-ISSN: 2215-3896

(Enero-Junio, 2022) . Vol 56(1): 209-228 DOI: https://doi.org/10.15359/rca.56-1.10

Open Access: www.revistas.una.ac.cr/ambientales e-mail: revista.ambientales@una.ac.cr Rodríguez-Miranda R., Palomo-Cordero L., Padilla-Mora M., Corrales-Vargas A., Wendel de Joode B. van

informarse en educación ambiental y buscar alternativas para dar respuesta a sus problemas o necesidades (Cabrera Cruz et al., 2018).

Se recomienda que las estrategias lúdicas sean cada vez más frecuentes en los centros educativos, pues este trabajo dejó en evidencia la reducida estimulación de tareas que involucran motora fina o patrones visomotores en los centros educativos de primaria, que es utilizada en preescolar pero casi ausente en la primeria. Esto señala un área por retomar desde la metodología participativa en las escuelas y los hogares, especialmente, porque actividades como el origami impulsa los períodos de atención. Además, técnicas como el origami, abren posibilidades para reconocer en el estudiantado participante: alegría por sus logros, frases pesimistas como "no puedo", emoción por elaborar su material, frustración por quedarse atrás, sentido de pertenencia o comparaciones entre pares.

Además, se recomienda emplear laboratorios para comprender el impacto de la salud ecosistémica y sus consecuencias sobre la biota, empleando materiales concretos. Esta metodología reveló la posibilidad de diseñar espacios flexibles y participativos en la enseñanza formal, donde el estudiantado pueda desarrollar una base para la indagación y la curiosidad científica, a través de preguntas, búsquedas y experiencias. En síntesis, las metodologías lúdicas, participativas y flexibles descritas en este trabajo, permitieron sensibilizar e informar a poblaciones rurales sobre los riesgos de exposición a plaguicidas. Estas estrategias representan una herramienta valiosa cuyo uso debería promoverse ante la atención de problemáticas de salud ambiental. La herramienta fue elaborada con base en el estado actual de conocimiento y podrá ser modificada y aplicada a prácticamente cualquier otro tema de educación ambiental.

\section{Agradecimientos}

Agradecemos a todos los directores y directoras de los centros educativos visitados para el desarrollo de este trabajo. Este trabajo fue parcialmente financiado por el Institute of Environmental Health Sciences (NIEHS), Estados Unidos, número de subvención R024 ES028526.

\section{Conflicto de intereses}

Las personas autoras declaran que han cumplido totalmente con todos los requisitos éticos y legales pertinentes, tanto durante el estudio como en la producción del manuscrito; que no hay conflictos de intereses de ningún tipo; que todas las fuentes financieras se mencionan completa y claramente en la sección de agradecimientos; y que están totalmente de acuerdo con la versión final editada del artículo.

\begin{tabular}{|c|c|c|}
\hline 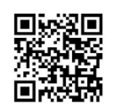 & (c) $\underset{\mathrm{BY}}{(1)} \mathrm{NG}_{\mathrm{SA}}$ & 224 \\
\hline
\end{tabular}




\section{Revista de CIENCIAS AMBIENTALES Tropical Journal of Environmental Sciences}

Revista de Ciencias Ambientales (Trop J Environ Sci) e-ISSN: 2215-3896

(Enero-Junio, 2022) . Vol 56(1): 209-228 DOI: https://doi.org/10.15359/rca.56-1.10 Open Access: www.revistas.una.ac.cr/ambientales e-mail: revista.ambientales@una.ac.cr Rodríguez-Miranda R., Palomo-Cordero L., Padilla-Mora M., Corrales-Vargas A., Wendel de Joode B. van

\section{Referencias}

Barraza, D., Jansen, K., van Wendel de Joode, B., \& Wesseling, C. (2011). Pesticide use in banana and plantain production and risk perception among local actors in Talamanca, Costa Rica. Environmental Research, 111(5), 708-717. https://doi.org/10.1016/j.envres.2011.02.009

Barraza, D., Jansen, K., Wesseling, C., \& van Wendel de Joode, B. (2020). Pesticide risk perceptions among bystanders of aerial spraying on bananas in Costa Rica. Environmental Research, 189, 1-10. https://doi.org/10.1016/j.envres.2020.109877

Bravo Durán, V., Malavassi Cruz, E. de la C., Herrera Ledezma, G., \& Ramírez Muñoz, F. (2013). Uso de plaguicidas en cultivos agricolas como agriculture pesticides use as tool for monitoring health. Uniciencia, 27(1), 351-376. https://www.revistas.una.ac.cr/index.php/ uniciencia/article/view/4960

Burgos, S., Yohannessen, K., Álvarez, A., Soc, A., Rebolledo, A., Educ, L., \& Valenzuela, M. T. (2017). Educación en salud a través del desarrollo de habilidades científicas en escolares chilenos. 59(3), 276-284. https://doi.org/10.21149/8177

Cabrera Cruz, E., Vigil Bocourt, J. L., \& Vilardell Casas, M. C. (2018). La educación ambiental comunitaria para los niños y niñas de la comunidad Soroa. Avances, 20(2), 122-132. https://dialnet.unirioja.es/servlet/articulo? codigo $=6513208$

Carreño Torres, S. (2018). Proyecto malabar circular: propuesta pedagógica artística para la enseñanza de malabares para fortalecer los procesos de motricidad y coordinación en el taller de circo y clown de la casa de la cultura del municipio de Chía [Tesis de Licenciatura, Corporación Universitaria Minuto de Dios]. Repositorio Institucional Uniminuto. https://repository. uniminuto.edu/handle/10656/6413

Córdoba Gamboa, L., Solano Díaz, K., Ruepert, C., \& Van Wendel de Joode, B. (2020). Passive monitoring techniques to evaluate environmental pesticide exposure: Results from the Infant's Environmental Health study (ISA). Environmental Research, 184, 109243. https://doi. org/10.1016/j.envres.2020.109243

Durán Ccorachua, Y., \& Paucar Meza, E. (2016). El origami como estrategia para desarrollar la coordinaciónmotríz fina en los niños de cinco años de la I.E. Konrad Adenauer Cusco. [Tesis de grado, Universidad Nacional de San Agustín]. Repositorio Institucional UNSA http://repositorio.unsa.edu.pe/handle/UNSA/5568

Echeverría-Sáenz S., Mena, F., Arias-Andrés, M., Vargas, S., Ruepert, C., Van den Brink, P. J., Castillo, L. E., \& Gunnarsson., J. S. (2008). In situ toxicity and ecological risk assessment of agro-pesticide runoff in the Madre de Dios River in Costa Rica. Environ Sci Pollut Res Int.,25(14), 13270-13282. https://doi.org/10.1007/s11356-016-7817-4

\begin{tabular}{|c|c|c|c|c|c|}
\hline 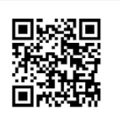 & (c) () & $\underbrace{}_{\text {AMBIFNTIISS }}$ & $\frac{10 \%}{\frac{0 \%}{20}}$ & $\frac{\text { UNA }}{\frac{\text { UNILERIDAD }}{\text { NACIONAL }}}$ & 225 \\
\hline
\end{tabular}




\section{Revista de CIENCIAS AMBIENTALES Tropical Journal of Environmental Sciences}

Revista de Ciencias Ambientales (Trop J Environ Sci) e-ISSN: 2215-3896

(Enero-Junio, 2022) . Vol 56(1): 209-228 DOI: https://doi.org/10.15359/rca.56-1.10 Open Access: www.revistas.una.ac.cr/ambientales e-mail: revista.ambientales@una.ac.cr Rodríguez-Miranda R., Palomo-Cordero L., Padilla-Mora M., Corrales-Vargas A., Wendel de Joode B. van

Felsot, A. S., Unsworth, J. B., Linders, J. B. H. J., Roberts, G., Rautman, D., Harris, C., \& Carazo, E. (2011). Agrochemical spray drift; assessment and mitigation-a review. Journal of Environmental Science and Health - Part B Pesticides, Food Contaminants, and Agricultural Wastes, 46(1), 1-23. https://doi.org/10.1080/03601234.2010.515161

Instituto de Desarrollo Rural. (2016). Caracterización del Territorio Limón-Matina. https://www. inder.go.cr/lima/Caracterizacion-territorio-Limon-Matina.pdf

Instituto Regional de Estudios en Sustancias Tóxicas \& Centro de Investigación y Docencia en Educación. (2018). Plaguicidas en el Caribe: Resultados de investigaciones del IRET-UNA en salud ambiental y humana [Video]. https://www.youtube.com/watch?v=FmVbb68Ds8E

Infantes y Salud Ambiental. (2019). En Matina nos Informamos y Transformamos: Corte documental para talleres 2019. [Video]. https://www.youtube.com/watch?v=zpZ_1H6-AHE\&t=32s

Asamblea Legislativa. (2003). Reglamento para las actividades de la Aviación Agrícola. La Gaceta. http://www.pgrweb.go.cr/scij/Busqueda/Normativa/Normas/nrm_texto_completo. aspx?param1=NRTC\&nValor $1=1 \&$ nValor2=52129\&nValor3=70809\&strTipM=TC

Asamblea Legislativa. (2007). Reglamento para la evaluación y clasificación de la calidad de cuerpos de agua superficiales. Gaceta. http://www.digeca.go.cr/legislacion/ decreto-33903-reglamento-para-la-evaluacion-y-clasificacion-de-la-calidad-de-cuerpos-de

López-Bolaños, L., Campos-Rivera, M., \& Villanueva-Borbolla, M. A. (2018). Compromiso y participación comunitaria en salud : aprendizajes desde la sistematización de experiencias sociales. Salud Pública Mex. 60(2). https://doi.org/10.21149/8460

Ministerio de Agricultura, Ministerio de Ganadería, Ministerio del Ambiente, Ministerio de Salud, \& Dirección Nacional de Aviación Civil y Agrocalidad. (Ecuador) (2014). Reglamento interministerial para el saneamiento ambiental agrícola. https://www.ecolex.org/es/details/legislation/acuerdo-no-365-reglamento-interministerial-para-el-saneamiento-ambiental-agricola-lex-faoc162538/

Mora, A. M., Córdoba, L., Cano, J. C., Hernandez-Bonilla, D., Pardo, L., Schnaas, L., Smith, D. R., Menezes-Filho, J. A., Mergler, D., Lindh, C. H., Eskenazi, B., \& de Joode, B. van W. (2018). Prenatal mancozeb exposure, excess manganese, and neurodevelopment at 1 year of age in the infants' environmental health (ISA) study. Environmental Health Perspectives, 126(5), 1-9. https://doi.org/10.1289/EHP1955

Mora, A. M., Hoppin, J. A., Córdoba, L., Cano, J. C., Soto-Martínez, M., Eskenazi, B., Lindh, C. H., \& van Wendel de Joode, B. (2020). Prenatal pesticide exposure and respiratory health outcomes in the first year of life: Results from the infants' Environmental Health (ISA) study. International Journal of Hygiene and Environmental Health, 225. 113474. https://doi. org/10.1016/j.ijheh.2020.113474

\begin{tabular}{|c|c|c|}
\hline 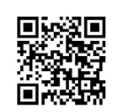 & (c) $(1)(0)$ & 226 \\
\hline
\end{tabular}




\section{Revista de CIENCIAS AMBIENTALES Tropical Journal of Environmental Sciences}

Revista de Ciencias Ambientales (Trop J Environ Sci) e-ISSN: 2215-3896

(Enero-Junio, 2022) . Vol 56(1): 209-228 DOI: https://doi.org/10.15359/rca.56-1.10 Open Access: www.revistas.una.ac.cr/ambientales e-mail: revista.ambientales@una.ac.cr Rodríguez-Miranda R., Palomo-Cordero L., Padilla-Mora M., Corrales-Vargas A., Wendel de Joode B. van

Morales Muñoz, P. (2012). Elaboración de material didáctico. Red Tercer Milenio. http://www. aliat.org.mx/BibliotecasDigitales/derecho_y_ciencias_sociales/Elaboracion_material_didactico.pdf

Programa de las Naciones Unidas para el Desarrollo \& Universidad de Costa Rica. (2020). Atlas de desarrollo humano cantonal | El PNUD en Costa Rica. https://www.cr.undp.org/content/ costarica/es/home/atlas-de-desarrollo-humano-cantonal.html

Pulido Santana, M. (2005). Juegos ecológicos, metodología para la educación ambiental. In Centro Nacioal de Educación Ambiental. https://www.miteco.gob.es/es/ceneam/articulos-de-opinion/2005_10pulido_tcm30-163629.pdf

Rodríguez, I., González, R., Morales, G., Azpeleta, C., Monreal, D., Fernández, R., Fernández-Santander, A., Palau, L., Rodríguez-Learte, A. I., Romero-Lorca, A., Santos, P., Sánchez, A., \& Gal-Iglesias, B. (2017). El aprendizaje a través del juego como herramienta en el diseño de actividades de valor añadido en un currículo integrador de Ciencias Biomédicas Básicas. Revista de La Fundación Educación Médica, 20(1), 23. https://scielo.isciii.es/scielo. php?script=sci_abstract\&pid=S2014-98322017000100023

Rodríguez, R., Palomo, L., Padilla, M., Corrales, A., \& van Wendel, B. (2020a). Propuesta metodológica de talleres: En Matina nos informamos y transformamos [video]

Rodríguez, R., Palomo, L., Padilla, M., Corrales, A., \& van Wendel, B. (2020b). Talleres participativos sobre riesgos en el uso de plaguicidas: Una construcción colectiva e interetaria. https:// doi.org/10.13140/RG.2.2.33418.18882

Secretería Ejecutiva de Planificación Sectorial Agropecuaria. (2015). BEA N²5. Boletín Estadístico Agropecuario. Serie cronológica, 2011-2014. Ministerio de Agricultura y Ganadería. http://www.infoagro.go.cr/BEA/BEA25/menu_super_produccion.html

Si Estrada, J. \& Hernández Ajú, V. (2015). Los niveles de atención en los niños de 11 a 12 años y su relación con el uso de origami [Tesis de Licenciatura, Universidad de San Carlos de Guatemala]. Repositorio USAC. http://www.repositorio.usac.edu.gt/2586/

Sistema Nacional de Información Territorial. (2019). Costa Rica. Cultivos 2017, escala 1:5000. Instituto Geográfico Nacional de Costa Rica. https://www.snitcr.go.cr/Metadatos/ full_metadata2?k=Y2FwYTo6SUdOXzU6OmN1bHRpdm9zMjAxN181aw

Springer, M., Vásquez, B., \& Castro, A. (2007). Bioindicadores de la Calidad del Agua. Universidad EARTH.

\begin{tabular}{|c|c|c|}
\hline 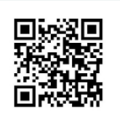 & (c) () & 227 \\
\hline
\end{tabular}




\section{Revista de CIENCIAS AMBIENTALES Tropical Journal of Environmental Sciences}

Revista de Ciencias Ambientales (Trop J Environ Sci) e-ISSN: 2215-3896

(Enero-Junio, 2022) . Vol 56(1): 209-228 DOI: https://doi.org/10.15359/rca.56-1.10 Open Access: www.revistas.una.ac.cr/ambientales e-mail: revista.ambientales@una.ac.cr Rodríguez-Miranda R., Palomo-Cordero L., Padilla-Mora M., Corrales-Vargas A., Wendel de Joode B. van

Till, C., Dudani, A., Córdoba, L., Cano, J. C., Green, R., Menezes-Filho, J. A., Schnaas, L., Smith, D. R., Lindh, C. H., \& Van Wendel de Joode, B. (2019). Caregiving and infants' neurodevelopment in rural Costa Rica: Results from the Infants' Environmental Health Study (ISA). NeuroToxicology, 74, 100-107. https://doi.org/10.1016/j.neuro.2019.06.002

Van Wendel de Joode, B., Mora, A. M., Lindh, C. H., Hernández-Bonilla, D., Córdoba, L., Wesseling, C., Hoppin, J. A., \& Mergler, D. (2016). Pesticide exposure and neurodevelopment in children aged 6-9 years from Talamanca, Costa Rica. Cortex, 85, 137-150. https://doi. $\operatorname{org} / 10.1016 /$ j.cortex.2016.09.003

Valerio-Hernández, V., Arguedas-Quirós, S., \& Aguilar-Arguedas, A. (2015). Educación ambiental en el marco de una estrategia participativa para atender el cambio climático a nivel local: Experiencias en Costa Rica. Revista de Ciencias Ambientales, 49(2), 1-12. https://doi. org/10.15359/rca.49-2.1

Zevallos Solís, L., Terrazo Luna, E., Piñas Zamudio, M., \& Ramos Berrocal, M. (2016). El origami en el desarrollo de la psicomotricidad de niños de la Institución Educativa Inicial "La Lupuna”, Ucayali. Apuntes de Ciencia \& Sociedad, 6(02), 137-142. https://doi.org/10.18259/ acs. 2016022

\begin{tabular}{|c|c|c|c|c|c|}
\hline 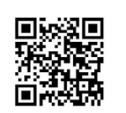 & (c) (i) $\$$ & $\overbrace{\text { AMBIENTIES }}$ & $\frac{1 \%}{2 \%}$ & $\frac{\text { UNA }}{\frac{\text { UNIEESIDAD }}{\text { NACRIONAL }}}$ & 228 \\
\hline
\end{tabular}

